\title{
Human Body Resistance and Temperature Measurement Device
}

\author{
Wara, S.T. ${ }^{a}$, Oghogho, I., ${ }^{b}$ Abayomi-Alli, A. ${ }^{c}$, Odikayor, C.D. ${ }^{d}$ \\ and Essien, M. S. ${ }^{\text {e }}$
}

Product Development / Energy Centre, Department of Electrical and Computer Engineering,
General Abdulsalami A. Abubakar College of Engineering, Igbinedion University Okada, Edo State,
Nigeria

adocwarati@yahoo.com, ${ }^{\text {boghoghoik@yahoo.com, }}$ ㄹabayomialli adebayo@yahoo.com ${ }^{\text {d }}$ dickinsodika@yahoo.com

\section{Keywords: Detector, Moisture, Resistance, Temperature and Linearization.}

\begin{abstract}
This paper discusses the design and construction of a human body resistance and temperature measurement device. The device measures the human body temperature and resistance when the sensing probes are placed in contact with the human skin. The design analysis was based on simple electronic circuit theories leading to specification and choice of components used for the construction of the system. After the construction and testing with various individuals the human body resistance and temperature was found to be within the ranges of $1 \mathrm{~K} \Omega$ to $210 \mathrm{~K} \Omega$ and $36.1^{0} \mathrm{C}$ to $37.5^{\circ} \mathrm{C}$ respectively. The paper discuses the various effect of current on the human body and their implication. The system can be adapted to various fields such as bio-technology, security (lie detector), safety equipment in industries and companies to determine insulation.
\end{abstract}

\section{Introduction}

Due to advancement in technology, human reliance on electricity is on the increase but shock hazards are the major drawback on its use. Safety devices and equipment that help to prevent or reduce shock possibilities are of increasing importance. Under stress or when exposed to conditions involving tension, the human body shows visible changes in its physiological responses such as heart beat rate, blood pressure, temperature, skin resistance to mention a few. With appropriate sensors and transducers these physical quantities can be converted into electrical or intermediate electrical quantities that can be measured by appropriate electronic equipment. The measurement of resistance in engineering practice is important to determine how much current a particular body can withstand on the application of a known voltage [1]. This knowledge helps an individual operating a particular machine or electronic device to select the right amount of insulation necessary to prevent shock hazards. Today measurement of body resistance is used to identify patients at risk of hypovolemia (reduced total body fluid) [2]. The measurement of human body temperature finds suitable application in the medical field and also it helps an individual determine whether or not his body temperature is within the acceptable temperature range. A temperature measurement device [3] which enables women to determine their ovulation by monitoring their body temperature is presently in use. Treatment of heart attack patients by subjecting them to a state of induced hypothermia which requires temperature measurement and monitoring is also being used today by health workers. [4]

\section{Methodology}

In order to achieve the aim set out, ongoing research on body temperature $[3,4]$ and resistance $[2,5]$ were studied and various design options and their cost implications were considered. The body resistance and temperature measurement device can be categorized into three major units. These are: the power supply unit, the detector and linearization unit and the output display unit. 


\section{Design of the Power Supply Unit}

The chosen step down transformer has the following ratings: Voltage rating (240V/12V), Current rating $(500 \mathrm{~mA})$. The chosen diode is D3SBA10, Peak reverse voltage: $800 \mathrm{~V}$, Forward voltage drop: $0.7 \mathrm{~V}$. A capacitor value of $4700 \mu \mathrm{F}, 25 \mathrm{~V}$ was used [6]. Two $9 \mathrm{~V}, 0.5 \mathrm{~A}$ batteries are used as an alternative to provide the $12 \mathrm{Volt}$ supply needed in the absence of A.C power supply.

\section{Design of the Detector Circuit}

The input resistors $\mathrm{R}_{1}$ and $\mathrm{R}_{2}=1 \mathrm{M}$ ohms making them as close as possible to the expected human body resistance. $\mathrm{C}_{1}$ is chosen to be $100 \mathrm{nF}$ to enable the removal of the induced mains hum found on the human body. Resistor $R_{3}$ is chosen to be $10 \mathrm{~K} \Omega$ to enable the high output of the emitter follower transistor $\mathrm{TR}_{1}$ to be safely reduced. The chosen transistors $\mathrm{TR}_{1}, \mathrm{TR}_{2}$ and $\mathrm{TR}_{3}$ are $\mathrm{C} 9014$. The collector-emitter voltage rating is $50 \mathrm{~V}$; the max collector power dissipation is $625 \mathrm{~mW}$. The maximum collector current is $150 \mathrm{~mA}$. [7]. $\mathrm{R}_{4}=470 \Omega, \mathrm{R}_{5}=47 \mathrm{~K} \Omega, \mathrm{VR}_{1}=478 \mathrm{~K} \Omega$. The circuit diagram is shown in Fig 1.

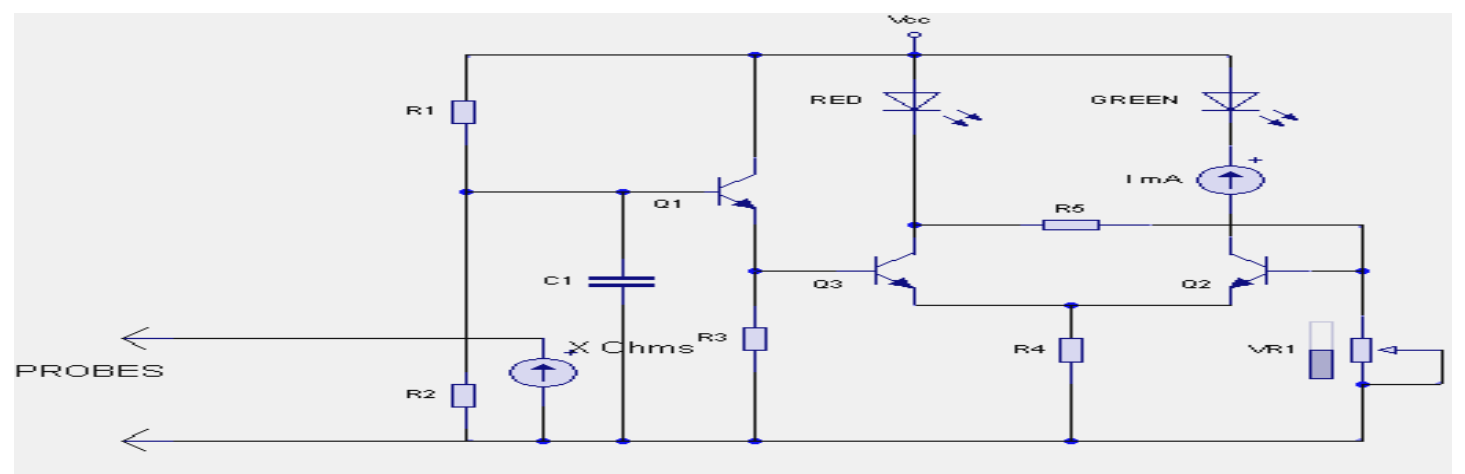

Fig.1 Resistance and moisture detection circuit

\section{Design of the Linearization Circuit}

The sensing circuit is excited by the reference voltage, $\mathrm{V}_{\mathrm{i} / \mathrm{p}}$ and is given by the expression

$\mathrm{V}_{\mathrm{i} / \mathrm{p}}=\mathrm{R}_{2} /\left(\mathrm{R}_{1}+\mathrm{R}_{2}\right) \mathrm{kV}_{\mathrm{cc}}$

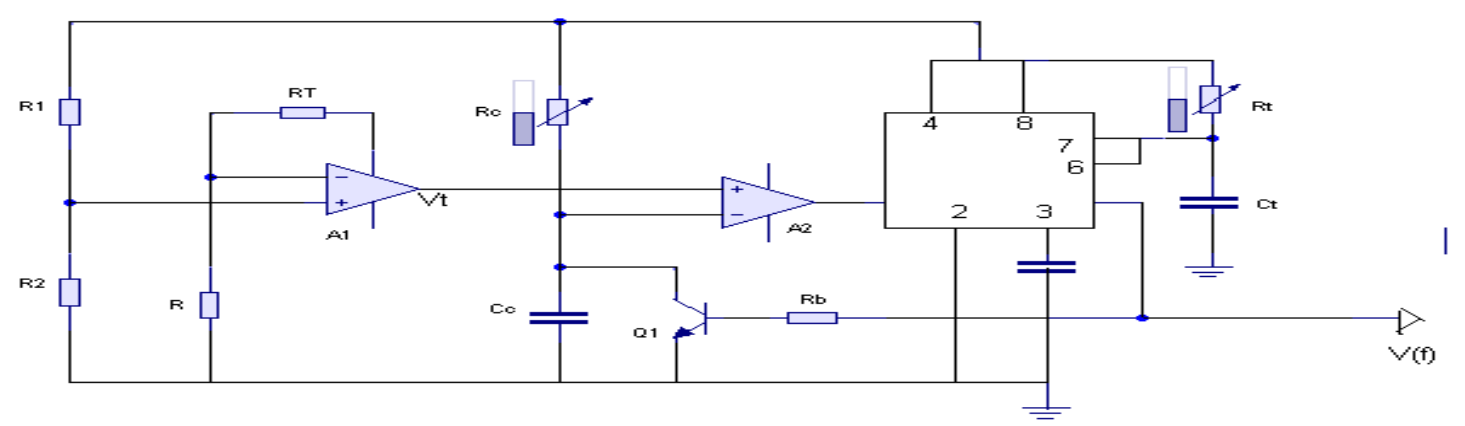

Fig.2. Linearization circuit

$\mathrm{K}=\mathrm{R}_{2} /\left(\mathrm{R}_{1}+\mathrm{R}_{2}\right)[8]$. From Fig.2, we have that

$\mathrm{V}_{\mathrm{t}}=\left[\left\{\mathrm{R}+\mathrm{R}_{\mathrm{t}}\right\} \mathrm{R}\right] \mathrm{V}_{\mathrm{ip}}=\left\{1+\mathrm{R}_{\mathrm{t}} / \mathrm{R}\right\} \mathrm{kV}_{\mathrm{cc}}$

$\mathrm{V}_{\mathrm{t}}$ is then fed to the comparator, $\mathrm{A} 2 . \mathrm{V}_{\mathrm{t}}$ controls the frequency of oscillation.

The chosen Op-amp is LM741, Maximum input voltage $18 \mathrm{~V}$, power dissipation $500 \mathrm{~mW}$. Using $\mathrm{V}_{\mathrm{cc}}$ $=7 \mathrm{~V}$ and Let $\mathrm{V}_{\mathrm{i} / \mathrm{p}}=0.6$ approx $10 \%$ of $\mathrm{V}_{\mathrm{cc}}$ \}, $\mathrm{R}_{1}$ is chosen to be $=1.2 \mathrm{~K}$ ohms

Then from Eq.1, $\mathrm{R}_{2}=\left[\mathrm{V}_{\mathrm{i} / \mathrm{p}} / \mathrm{R}_{1}\right] /\left[\mathrm{V}_{\mathrm{cc}}-\mathrm{V}_{\mathrm{i} / \mathrm{p}}\right]=[0.6 \mathrm{X} 1200] /[7-0.6]=112.5 \mathrm{ohms}$

$\mathrm{R}_{2}$ is therefore chosen to be 120 ohms. Thus $\mathrm{K}=120 / 1320=0.09, \mathrm{~K}=0.09$. 
General purpose N.T.C disc thermistor is used. Resistance tolerance $= \pm 10 \%$ at $25^{\circ} \mathrm{C}$, Maximum ambient temperature $=1250 \mathrm{C}, \mathrm{R}_{0}$ at $25^{\circ} \mathrm{C}=10 \mathrm{~K} \Omega$. [7] Temperature range $=-30^{\circ} \mathrm{C}$ to $125^{\circ} \mathrm{C}$ $\mathrm{t}_{\mathrm{c}} /\left(\mathrm{R}_{\mathrm{c}} \mathrm{C}_{\mathrm{c}}\right)=\ln \left(\mathrm{R} /\left[\mathrm{R}\{1-\mathrm{K}\}-\mathrm{KR}_{\mathrm{t}}\right]\right)$ and $\mathrm{R} /\left[\mathrm{R}\{1-\mathrm{K}\}-\mathrm{KR}_{\mathrm{t}}\right]=\mathrm{e}^{\mathrm{tc} /(\mathrm{RcCc})}[9]$

$\left.\mathrm{R}=\mathrm{KR}_{\mathrm{t}} \mathrm{e}^{\mathrm{tc} /(\mathrm{RcCc})) /[}\{1-\mathrm{K}\} \mathrm{e}^{\mathrm{tc} /(\mathrm{RcCc})}-1\right]$

$\mathrm{R}=0.09 \mathrm{X} 18 \mathrm{~K} /\left[\{1-0.09\}-\mathrm{e}^{-0.2 \mathrm{~m} /(100 \mathrm{~K} \times 21.21)}\right]=18.848 \mathrm{~K}$ ohms

\section{Design of the Comparator and Monostable Unit}

Fig 3. shows the Comparator and monostable unit

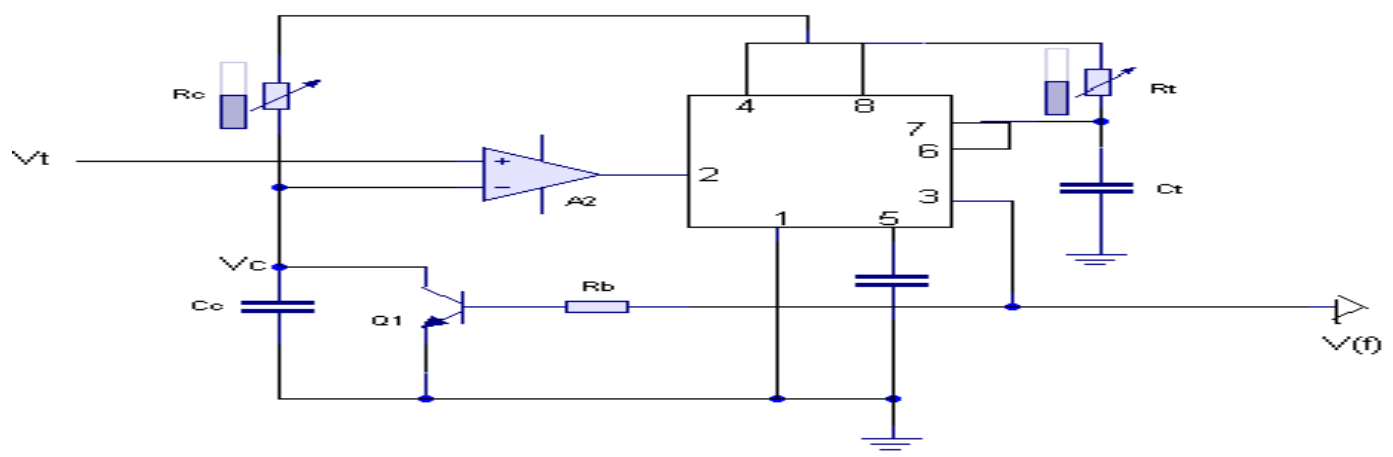

Fig.3: Comparator and monostable unit.

When $\mathrm{V}_{\mathrm{c}}=\mathrm{V}_{\mathrm{t}}$, the comparator $\mathrm{A}_{2}$ triggers the monostable circuit. The output pulse of the mono stable circuit with duration, $t_{w}$, switches $O N$ transistor $Q_{1}$ thereby discharging the capacitor, $C_{c}$. After $t_{w}, C_{c}$ is charged up again towards $V_{c c}$ until it reaches $V_{t}$. This process is repeated continuously and a series of rectangular pulse, whose frequency depends on temperature, is produced at its output. [8]

$\mathrm{V}_{\mathrm{c}}=\mathrm{V}_{\mathrm{cc}}\{1-\mathrm{e}-(\mathrm{t} / \tau)\}$

Where $\tau=R_{c} C_{c}$. The charging time $t_{c}$ is obtained when $V_{t}=V_{c}$. Thus by equating Eq. 2 and Eq. 4 together we have $\mathrm{K}\left\{1=\left[\mathrm{R}_{\mathrm{t}} / \mathrm{R}\right]\right\}=1-\mathrm{e}^{-(\mathrm{t} / \mathrm{r})}$

Where $\mathrm{t}_{\mathrm{c}}=\mathrm{R}_{\mathrm{c}} \mathrm{C}_{\mathrm{c}} \ln \left(\mathrm{R} /\left[\mathrm{R}\{1-\mathrm{K}\}-\mathrm{KR}_{\mathrm{t}}\right.\right.$

For a linear relationship to exist between frequency and temperature, then $\mathrm{KR}_{\mathrm{t}}=0$ and

$\mathrm{tc}=\mathrm{R}_{\mathrm{c}} \mathrm{C}_{\mathrm{c}} \ln \mathrm{R} /[\mathrm{R}\{1-\mathrm{K}\}]=\mathrm{R}_{\mathrm{c}} \mathrm{C}_{\mathrm{c}} \ln \{1 /[1-\mathrm{K}]\}$

Also $t_{c}=t_{w}$ but $t_{w}$ is set by the monostable timing parameter, giving by

$\mathrm{t}_{\mathrm{w}}=1.1 \mathrm{R}_{\mathrm{t}} \mathrm{C}_{\mathrm{t}}$

The chosen monostable is NE555, the supply voltage is $18 \mathrm{~V}$, the minimum current is $20 \mathrm{~mA}$, Operating temperature $0-700 \mathrm{C}$. [7] The pulse width for the comparator, $t_{\mathrm{c}}$ must be equal to the pulse width of the monostable, $t_{w}$ such that $t_{w}=t_{c}$. Let the pulse width $t_{w}=t_{c}=0.2 m s e c$ in order to have a fast response and the chosen value of $\mathrm{R}_{\mathrm{c}}$ be $=100 \mathrm{~K} \Omega$. Then from Eq. 6

$\left.\mathrm{Cc}=\mathrm{t}_{\mathrm{c}} /[\mathrm{Ra} \ln \{1 / 1-\mathrm{K}\}]=0.2 \mathrm{~ms} /[105 \ln \{1 / 1-0.09)\}\right]=[2 / \ln \{1 / 0.09\}] \mu \mathrm{F}$

$\mathrm{Cc}=21.21 \mu \mathrm{F}$, the chosen capacitor is $470 \mathrm{nF}, 50 \mathrm{~V}$. For the monostable, by chosen $\mathrm{Ct}=0.01 \mu \mathrm{F}$ and $\mathrm{t}_{\mathrm{c}}=\mathrm{t}_{\mathrm{w}}=0.2 \mathrm{~ms}$ for fast response, then from Eq. 8 we have that

$\mathrm{R}_{\mathrm{t}}=\mathrm{t}_{\mathrm{w}} / 1.1 \mathrm{Ct}=0.02 \mathrm{~ms} /[1.1 \times 0.01 \times 10-6]=18 \mathrm{~K} \Omega$, therefore, $\mathrm{R}_{\mathrm{t}}$ is chosen to be $=18 \mathrm{~K} \Omega$ 
The chosen transistor is $\mathrm{BC} 108$, the collector-emitter voltage drop is $0.65 \mathrm{~V}$, the power rating is $300 \mathrm{~mW}$, and the current gain is 110 . V (f) will vary between $0 \mathrm{~V}$ and $\mathrm{Vcc}\left(0 \leq \mathrm{V}(\mathrm{f}) \leq \mathrm{V}_{\mathrm{cc}}\right)$. The maximum current, the 555 timer can deliver is $20 \mathrm{~mA}$, Thus, if $\mathrm{V}(\mathrm{f})=\mathrm{V}_{\mathrm{cc}}=7 \mathrm{~V}, \mathrm{I}_{\mathrm{B}}=\mathrm{I}_{\mathrm{c}}$ of the timer (20mA) and $\beta=80 .[7]$

Thus $\mathrm{R}_{\mathrm{B}}=\left(\left[\mathrm{V}(\mathrm{f})-\mathrm{V}_{\mathrm{BE}}\right] / \mathrm{I}_{\mathrm{c}}\right) \beta$

$\mathrm{R}_{\mathrm{B} 1}=\left[\left\{\mathrm{V}(\mathrm{f})-\mathrm{V}_{\mathrm{BE}}\right] / \mathrm{I}_{\mathrm{c}}\right) \beta=\left[\mathrm{V}(\mathrm{f})-\mathrm{V}_{\mathrm{BE}}\right] / \mathrm{I}_{\mathrm{B}}=[7-0.6] / 20 \mathrm{~mA}=320 \Omega$

If we use minimum current from monostable is $10 \mathrm{~mA}$. Then $\mathrm{R}_{\mathrm{B} 2}=[7-0.6] / 10 \mathrm{~mA}=640 \Omega$. The chosen value of $R_{B}$ should be between $320<R_{B} \leq 640 \Omega$. $R_{B}$ is chosen as $410 \Omega$. The complete circuit diagram of the human body resistance and temperature measurement device is shown in Fig. 4.

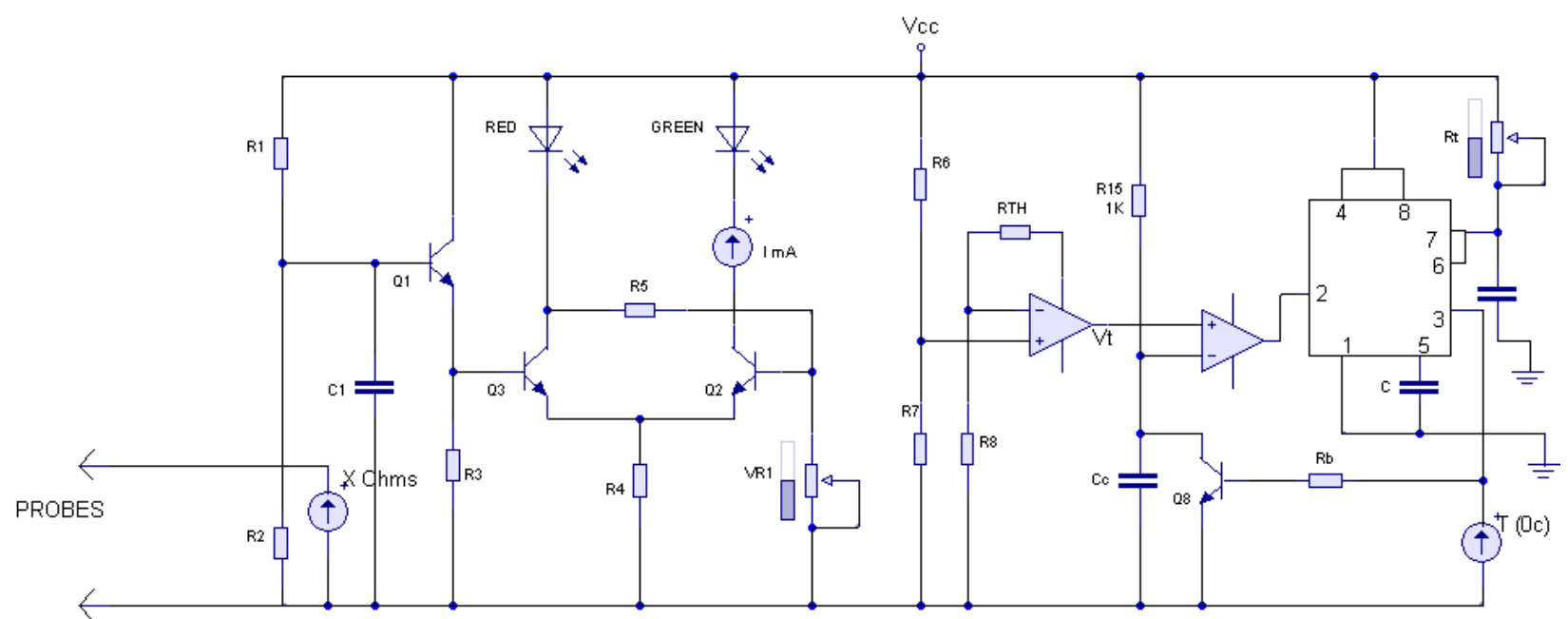

Fig.4: Complete circuit diagram of the human body resistance and temperature measurement device

\section{Principle of Operation}

In the detector circuit, when the probes are in contact with the human body, a meter connected across measures the body resistance. Under normal body resistance value, the green LED comes on because the base current of its biasing transistor is higher than the base current of the red LED's biasing transistor, thus the red LED stays off. However when there is a change in the body resistance signaled by the presence of humidity or moisture on the skin which reduces the skin resistance, the comparator circuit consisting of the green and red LED biasing transistors switches and the red LED comes on while the green LED turns off. The third transistor is basically an emitter follower providing large outputs for various values of inputs. The resistors help in either voltage dividing or in biasing of the transistors. The capacitor $\mathrm{C}_{1}$ is a hum suppressor reducing the induced $50 \mathrm{~Hz}$ supply frequency from human body. In the linearization circuit, the thermistor acts as the temperature sensor. It responds slowly and non-linearly to temperature changes, hence the need for a linearization circuit to linearize its output. The thermistor is part of a voltage divider circuit of the first comparator whose output triggers the multivibrator that sends out rectangular pulses set by the pulse width which is read by the temperature meter.

\section{Tests}

The voltage divider resistors and potentiometer were used to set input into the comparator circuit formed by two transistors thereby setting the green LED to ON when the circuit is powered. First, the sensing probes are then placed on the dry human skin and the result of the indicators is noted. Then the sensing probes are placed on a humid skin and the result noted. Second, a soldering iron is heated up and the sensing probe is placed near to the soldering iron. The result of the indicators is also noted. Third, the sensing probes are placed on moist substance and the result noted. The output 
display meters and the green and red LED's were closely monitored as the tests were being carried out. When the circuit is powered on, the temperature meter deflects. This is environmental temperature.

\section{Results and Discussion}

The table below shows the results of placing the probes on different individuals. When the system is turned on the green LED remains on and the resistance meter reads full scale deflection of about $1 \mathrm{M} \Omega$, the current meter reads null and the temperature meter shows the atmospheric temperature. When the sensing probe is placed on a dry skin the green LED remains on and the resistance meter reads the body resistance in ohms, the current meter reads null and the temperature meter shows the body temperature. When the sensing probe is then placed on a humid skin, the resistance meter deflects towards zero depending on the level of humidity or moisture, showing the reduction of the body resistance. The temperature meter deflects depending on the temperature it senses and the current meter deflects indicating that current is flowing through the circuit. The value of $1 \mathrm{M} \Omega$ standard resistor produces full scale deflection and keeps the green LED on. The values of lower standard resistors produce reduced deflection and turn on the red LED. When placed on a moist substance the device switches and the green LED goes off while the red LED comes on. Table 1 shows a summary of the results. Note that the resistance is measured between the two fingers. The results show that the presence of moisture can greatly reduce the body resistance and hence increase the risk of such an individual to electric shock.

Table 1: Tabulated results of certain individual

\begin{tabular}{|l|l|l|l|l|}
\hline $\begin{array}{l}\text { Indivi } \\
\text { dual }\end{array}$ & $\begin{array}{l}\text { Body resistance } \\
\text { without } \\
\text { moisture }[\Omega]\end{array}$ & $\begin{array}{l}\text { Body resistance with } \\
\text { moisture }[\Omega]\end{array}$ & $\begin{array}{l}\text { Body temp } \\
\text { measured by the } \\
\text { device }\left[{ }^{0} \mathrm{C}\right]\end{array}$ & $\begin{array}{l}\text { Body temp } \\
\text { measured by } \\
\text { thermometer } \\
{\left[{ }^{0} \mathrm{C}\right]}\end{array}$ \\
\hline A & $210 \mathrm{~K}$ & $1 \mathrm{~K}$ & 36.1 & 36.4 \\
\hline $\mathrm{B}$ & $189 \mathrm{~K}$ & $1.2 \mathrm{~K}$ & 36.3 & 36.2 \\
\hline $\mathrm{C}$ & $56 \mathrm{~K}$ & $5.5 \mathrm{~K}$ & 37 & 37.6 \\
\hline $\mathrm{D}$ & $70 \mathrm{~K}$ & $4 \mathrm{~K}$ & 37.5 & 37.1 \\
\hline $\mathrm{E}$ & $80 \mathrm{~K}$ & $6 \mathrm{~K}$ & 37.4 & 36.9 \\
\hline
\end{tabular}

Table 2 shows the summary of the effect of current on the human body [10]. It can be seen from the table that women are more at risk of electric shock when exposed to the same amount of current as men. This table clearly shows the need to put on the necessary insulation to prevent electric shock.

Table 2: The effect of current on human beings

\begin{tabular}{|l|l|l|l|}
\hline BODILY EFFECT & DIRECT CURRENT (DC) & $60 \mathrm{~Hz}$ AC & $10 \mathrm{~Hz} \mathrm{AC}$ \\
\hline \multirow{2}{*}{ Slight sensation felt at hand } & Men $=1.0 \mathrm{~mA}$ & $0.4 \mathrm{~mA}$ & $7 \mathrm{~mA}$ \\
\cline { 2 - 4 } & Woman $=0.6 \mathrm{~mA}$ & $0.3 \mathrm{~mA}$ & $5 \mathrm{~mA}$ \\
\hline \multirow{2}{*}{ Threshold of perception } & Men $=5.2 \mathrm{~mA}$ & $1.1 \mathrm{~mA}$ & $12 \mathrm{~mA}$ \\
\cline { 2 - 4 } & Woman $=3.5 \mathrm{~mA}$ & $0.7 \mathrm{~mA}$ & $8 \mathrm{~mA}$ \\
\hline \multirow{2}{*}{$\begin{array}{l}\text { Painful, but voluntary muscle } \\
\text { Painful, unable to let go of wires }\end{array}$} & Men $=62 \mathrm{~mA}$ & $9 \mathrm{~mA}$ & $55 \mathrm{~mA}$ \\
\cline { 2 - 4 } & Woman $=41 \mathrm{~mA}$ & $6 \mathrm{~mA}$ & $37 \mathrm{~mA}$ \\
\cline { 2 - 4 } & Woman $=51 \mathrm{~mA}$ & $16 \mathrm{~mA}$ & $75 \mathrm{~mA}$ \\
\hline \multirow{2}{*}{ Severe pain, difficulty breathing } & Men $=90 \mathrm{~mA}$ & $23 \mathrm{~mA}$ & $94 \mathrm{~mA}$ \\
\cline { 2 - 4 } & Woman $=60 \mathrm{~mA}$ & $15 \mathrm{~mA}$ & $63 \mathrm{~mA}$ \\
\hline \multirow{2}{*}{$\begin{array}{l}\text { Possible heart fibrillation after } 3 \\
\text { seconds }\end{array}$} & Men $=500 \mathrm{~mA}$ & $100 \mathrm{~mA}$ & \\
\cline { 2 - 3 } & Men $=500 \mathrm{~mA}$ & $100 \mathrm{~mA}$ & \\
\hline
\end{tabular}




\section{Conclusion}

The aim of this work was to design and construct a body resistance and temperature measurement device. The required circuit has been designed, constructed and found to be working satisfactorily. The device is able to measure the human body resistance and temperature by means of a sensing probe. The results obtained compares well with the human body resistance results obtained from other research work which is about $10 \mathrm{~K}$ to $100 \mathrm{k}$ between dry fingers and as low as $300 \Omega$ between wet fingers $[11,12]$. The output is read out across meters and LEDs. The device finds application in homes and industries as a safety, moisture detector and a temperature measurement device. The device can also be modified to act as a lie-detector.

\section{References}

1. http://www.allaboutcircuits.com

$21 / 01 / 2007$

2. http://cat.inist.fr/?aModele $=$ affichen\& cpsidt $=17279555$

$03 / 12 / 2004$

3. http://www.freepatentonline.com/4557273.html

$03 / 12 / 2008$

4. http://www.medicalnewstoday.com/articles/104081.php

$03 / 12 / 2008$

5. Douglas J. C. et al "Validity of Devices that Access the Body Temperature During Outdoor Exercise in the Heat" Journal of Athletic Training 2007 July - Sept., 42 (3): pp333342

6. Wara S. T., Orovwode H. E, Mohammed O. A. "Design Construction and Simulation of an Electronic Water Level Controller" International Research Journal in Engineering Science and Technology. Volume 4 No1, 2007 pp 107,108

7. http://www.datasheetcatalogue.com,

8. http://www.semiconductor.philips.com,

$19 / 04 / 2007$

9. Theraja B.L., Theraja A.K., "A textbook of electrical technology" illustrative multicolored edition, published by S.C. Chand and company, 2005. pp 375-378.

10. http://www.bassengineering.com/E_Effect.htm

$03 / 12 / 2008$

11. http://van.physics.uiuc.edu/qa/listing.php?id=6793

$03 / 12 / 2008$

12. http://westarenergy.apogee.net/fshrrh.asp

$03 / 12 / 2008$ 
Advances in Materials and Systems Technologies II

doi:10.4028/3-908454-12-3

Human Body Resistance and Temperature Measurement Device

doi:10.4028/3-908454-12-3.153 